Gynecologic and

Obstetric Investigation
Gynecol Obstet Invest 2014;77:150-155

DOI: $10.1159 / 000358831$
Received: November 1, 2013

Accepted after revision: January 18, 2014

Published online: February 27, 2014

\title{
Polymorphisms of the Endothelial Nitric Oxide Synthase Gene in Preeclampsia in a Han Chinese Population
}

\author{
Yunqin Chen ${ }^{\mathrm{a}}$ Dongguo Wang ${ }^{\mathrm{b}}$ Meiqian Zhou ${ }^{\mathrm{a}}$ Xiangjuan Chen ${ }^{\mathrm{a}}$ \\ Jiayu Chen ${ }^{\mathrm{c}}$ \\ a Department of Gynecology and Obstetrics, Wenzhou Medical University Affiliated No. 1 Hospital, Wenzhou, \\ ${ }^{b}$ Department of Laboratory Medicine, Taizhou Municipal Hospital of Taizhou University and the Institute of \\ Molecular Diagnostics of Taizhou University, and ' Department of Laboratory Medicine, Medical College of Taizhou \\ University and the Institute of Molecular Diagnostics of Taizhou University, Taizhou, PR China
}

\section{Key Words}

Endothelial nitric oxide synthase · Polymorphism .

Preeclampsia $\cdot$ Nitric oxide $\cdot$ Han Chinese

\begin{abstract}
Background/Aims: The endothelial nitric oxide synthase (eNOS) gene has been enlisted by previous research as a candidate gene of preeclampsia predisposition. This study investigates the specific roles of 3 polymorphisms of the eNOS gene in a population of Chinese origin from mainland China. Methods: We studied the association of 3 commonly studied polymorphisms of the eNOS gene, namely $4 \mathrm{~b} / \mathrm{a}, \mathrm{T}-$ $786 \mathrm{C}$ and Glu298Asp, in a case-controlled sample of $220 \mathrm{pa}-$ tients diagnosed with preeclampsia and 200 healthy controls. The association between eNOS polymorphisms and preeclampsia was evaluated by performing genotyping for the eNOS variants and calculating odds ratios (OR) and $95 \%$ confidence intervals. The plasma nitrite concentration in participants was determined to examine how 3 eNOS polymorphisms affect plasma nitric oxide (NO) concentrations in pregnant women. Results: The frequencies of both the variant 298Asp allele and eNOS 4a allele were significantly lower in preeclamptic women than in the control group and
\end{abstract}

had a significantly lower OR. The variant 298Asp allele and eNOS $4 a$ are strongly associated with higher plasma NO concentrations in pregnant women. Conclusions: Polymorphisms in the eNOS gene may be protective against preeclampsia in a Chinese population, and this protective effect may be associated with NO formation in plasma in pregnant women.

(c) 2014 S. Karger AG, Basel

\section{Introduction}

Preeclampsia is a common complication of pregnancy that has affected up to $10 \%$ of all pregnancies in the developing countries and becomes a severe risk factor for both maternal and neonatal morbidity and mortality [1, 2]. Although the exact etiology of preeclampsia has not been thoroughly understood, a variety of genetic and environmental factors have been proposed to play a role in the pathogenesis and development of preeclampsia $[3,4]$. The incident risk of preeclampsia for daughters of preeclamptic mothers is reported to be $20-40 \%$, and $11-37 \%$ for sisters of preeclamptic women, which is even higher for twin sisters (22-47\%) [5].

\section{KARGER}

E-Mail karger@karger.com

www.karger.com/goi
(C) 2014 S. Karger AG, Base

0378-7346/14/0773-0150\$39.50/0 
Mounting evidence suggests that reduced nitric oxide (NO) formation is often linked with the hypertensive disorders of pregnancy, particularly preeclampsia [6-10]. Some previous study has investigated whether genetic mutations in the endothelial NO synthase (eNOS) gene could affect the impaired NO formation which further connects with preeclampsia, and has attempted to establish or dismiss the role of eNOS as a candidate gene for the pathogenesis and development of preeclampsia. Impairment of NO-mediated vasodilatation has been suggested to play important roles in the development of such a condition [11, 12]. In a linkage study, Arngrimsson et al. [13] identified the region of chromosome $7 \mathrm{q} 36$ which encodes the eNOS gene and could serve as a possible candidate region responsible for pregnancy-induced hypertension.

The eNOS gene consists of 26 exons on chromosome 7. There are several eNOS gene polymorphisms, and at least 3 of these have been proposed to link with distinct NO levels in the blood. A missense mutation in exon 7 of the eNOS gene leads to the replacement of guanine by thymine (G894T), resulting in the single-nucleotide polymorphism in exon 7 (Glu298Asp, rs1799983) [14]. Molecular studies have suggested that intact eNOS Asp298 has an equivalent enzymatic effect with eNOS Glu298, but when it is under selective proteolysis in native cells and tissues the steady activity level of eNOS may be diminished in carriers of this allele [15]. The other two most common variants include: an insertion-deletion polymorphism within intron $4(4 \mathrm{a} / \mathrm{b})$ comprised of 2 alleles (the $\mathrm{a}^{*}$-deletion allele with 4 tandem 27 -bp repeats and the $b^{*}$-insertion allele with 5 repeats) and a T-786C substitute in the promoter region (rs2070744) [16].

The association studies between eNOS variants and preeclampsia have until now produced interesting yet controversial results, and the replication study in this area is far from being sufficient $[17,18]$. Therefore, the status of association for the eNOS variants remains less understood. And what is more important, there is regretfully a lack of replication from the Chinese population, except that one study from Taiwan reported that polymorphisms in the eNOS Glu298Asp and intron 4 variant may be protective against preeclampsia in the Chinese population, but the T-786C association study was missing in the same population; in addition, participants in that study are not all from the Han Chinese population, but also from other Chinese ethnic groups. Thus, in our current study, we aimed to replicate similar research on the association between preeclampsia and the three most commonly investigated eNOS polymorphisms (4b/a, T-786C and Glu298Asp) in a homogeneous population of Han Chinese origin (mainland China). These variants were selected because of their potential functional roles and their high minor allele frequencies [19-21].

In this study, we also tested the NO concentration in the plasma in all the participants, and aimed to examine how the three eNOS polymorphisms described above affect plasma nitrite concentrations in healthy pregnant women and in preeclamptic women.

\section{Materials and Methods}

\section{Participants}

A total of 220 cases of preeclampsia patients and 200 healthy female controls were recruited from the outpatient and inpatient sections of the Department of Obstetrics and Gynecology of the First Affiliated Hospital of Wenzhou Medical University. Preeclampsia was defined as significant hypertension level, with systolic blood pressure $\geq 140 \mathrm{~mm} \mathrm{Hg}$ or diastolic blood pressure $\geq 90$ $\mathrm{mm} \mathrm{Hg}$ and 24-hour proteinuria $>300 \mathrm{mg}$ at or after 20 weeks' gestation $[22,23]$. The study protocol was reviewed and approved by the Ethics Committee of our hospital, and all participants signed a written informed consent. All controls had a normal pregnancy without complications, and there were no conditions of preeclampsia shown in their medical history. The controls had no blood relations with the test group, and all were delivered at term. All participants included in the study were of Han Chinese origin whereas women with previous medical histories of renal disease, metabolic disorders or diabetes were excluded from the patient sample. Blood samples of all the patients were tested by biochemical measurements and their DNA extractions were also taken for testing.

\section{DNA Analysis}

Genomic DNA was extracted from the whole blood of the patients' blood samples using the PureLink ${ }^{\circledR}$ Total RNA Blood Kit (Life Technologies, Invitrogen China Ltd.) according to the instructions on the user manual. Genotyping of each variant was performed by amplification from 50 to $500 \mu \mathrm{l}$ of genomic DNA. The primer sequences utilized and the laboratory conditions for genotyping including polymerase chain reaction, restriction enzymes and agarose electrophoresis for each eNOS polymorphism have been previously described [19-21]. Genotyping was performed by laboratory staff blinded to the patients' clinical status.

\section{Measurement of Plasma Nitrite Concentrations}

Plasma aliquots were analyzed in triplicate for their nitrite content using an ozone-based chemiluminescence assay as previously described [24-26]. Briefly, $200 \mu \mathrm{l}$ of plasma sample was injected into a solution of acidified tri-iodide, purged with nitrogen in line with a gas phase chemiluminescence NO analyzer (ArrowSTRAIGHTTM ${ }^{\mathrm{T}}$, Shelfscientific, Division of Lazar Research Laboratories, USA). Approximately $8 \mathrm{ml}$ of tri-iodide solution, comprised of $2 \mathrm{~g}$ of potassium iodide and $1.3 \mathrm{~g}$ of iodine dissolved in $40 \mathrm{ml}$ of water with $140 \mathrm{ml}$ of acetic acid, were put into the purge vessel where the plasma samples were injected. The tri-iodide solution could reduce nitrites to $\mathrm{NO}$ gas, which is detectable in the NO analyzer. 
Statistical Analyses

Statistical analyses were performed using the statistical package SPSS 19.0. The $\chi^{2}$ test or an independent Student $t$ test was employed to examine the differences between groups, whenever appropriate. The gene-counting method was used in the estimation of the allele frequencies. The frequencies of the genotypes and the alleles were compared between the test group and the control group by the $\chi^{2}$ test, where appropriate. The $95 \%$ confidence intervals (CI) and odds ratio (OR) were also estimated. The $\chi^{2}$ test was performed for the deviation of genotype distribution from the Hardy-Weinberg equilibrium. Risk factors were adjusted by multivariate logistic regression analysis, in which preeclampsia was a dependent variable and independent variables were history of preeclampsia, age and eNOS polymorphisms.

\section{Results}

\section{Characteristics of the Study Patients}

The clinical characteristics of the participants are shown in table 1 . There were no differences in maternal age between preeclamptic patients and controls. As expected, gestational age was significantly lower in preeclamptic women, and the systolic and diastolic blood pressures and primiparity were significantly higher in the test group than in the control group. Birth weight was slightly lower in preeclamptic women, but the difference was not significant.

\section{eNOS Variant Allele Frequency and Genotype \\ Distribution}

The distributions of the eNOS $4 \mathrm{~b} / \mathrm{a}, \mathrm{T}-786 \mathrm{C}$ and Glu298Asp genotypes were compared between preeclamptic patients and controls and are presented in table 2. Allele frequencies of all three polymorphisms were in HardyWeinberg equilibrium ( $p>0.05)$.

Frequencies of the bb, ba and aa genotypes were 80.5, 18.5 and $1.0 \%$ in preeclamptic patients and $68.9,28.3$ and $2.78 \%$ in healthy controls, respectively. The a allele frequencies were 11.2 and $16.9 \%$ in preeclamptic patients and in healthy controls, respectively. Significant differences in the genotype distribution or allele frequencies between patients and controls were found $(p<0.05)$. The $\mathrm{b}$ allele might be a risk factor for preeclampsia (OR = $1.768 ; 95 \% \mathrm{CI}=0.168-2.731 ; \mathrm{p}<0.01)$.

Genotype frequencies of the Glu298Asp polymorphism in healthy controls were $61.1 \%$ for GluGlu, $27.8 \%$ for GluAsp and $11.1 \%$ for AspAsp. On the other hand, in preeclamptic patients, genotype frequencies were $71 \%$ for GluGlu, 24.5\% for GluAsp and 4.5\% for AspAsp; statisti$\mathrm{cal}$ analysis showed significant differences $(\mathrm{p}<0.05)$. The Asp allele frequencies were 25.0 and $16.7 \%$ in healthy
Table 1. Clinical characteristics of preeclamptic patients and controls

\begin{tabular}{lccc}
\hline & $\begin{array}{c}\text { Preeclampsia } \\
(\mathrm{n}=200)\end{array}$ & $\begin{array}{c}\text { Controls } \\
(\mathrm{n}=180)\end{array}$ & p value \\
\hline $\begin{array}{l}\text { Age, years } \\
\text { Gestational age, weeks }\end{array}$ & $29.1 \pm 6.5$ & $27.2 \pm 6.1$ & $>0.05$ \\
$\begin{array}{l}\text { Birth weight, g } \\
\text { Diastolic blood pressure, } \\
\quad \text { mm Hg }\end{array}$ & $2,769 \pm 832$ & $3,011 \pm 756$ & $>0.05$ \\
$\begin{array}{l}\text { Systolic blood pressure, } \\
\quad \text { mm Hg }\end{array}$ & $96.3 \pm 8.2$ & $70.2 \pm 8.3$ & $<0.01$ \\
$\begin{array}{l}\text { Primiparity, \% } \\
\text { Family history of }\end{array}$ & $151.3 \pm 13.6$ & $112.6 \pm 10.7$ & $<0.01$ \\
$\quad$ preeclampsia, \% & 0.42 & 87 & $>0.05$ \\
\hline
\end{tabular}

controls and preeclampsia patients, and the Glu allele conferred a significantly higher risk compared to the Asp allele $(\mathrm{OR}=1.657 ; 95 \% \mathrm{CI}=1.162-2.362 ; \mathrm{p}<0.05)$.

As for the T-786C variant, no significant differences in the genotype distribution or allele frequencies between patients and controls were found ( $p>0.05$ ), so we did not calculate the OR (table 2).

\section{Relationship between Variants and Nitrite \\ Concentration in Plasma}

Plasma NO concentration was examined to further understand the underlying mechanism about how the variants of eNOS affected the NO formation in preeclampsia patients and healthy women. Consistent with OR analysis, Glu298Asp and intron 4 polymorphisms had significant effects on the plasma nitrite concentrations; higher nitrite levels were found in both healthy and preeclamptic women with the AspAsp genotype compared with those with the GluGlu genotype and with the $4 \mathrm{a} 4 \mathrm{a}$ genotype compared with those with the $4 \mathrm{~b} 4 \mathrm{~b}$ genotype ( $<<0.05$; fig. 1$)$. No effect of T-786C on plasma nitrite concentrations was found in preeclampsia and healthy women in the Chinese population in the current study (fig. 1 ; all $\mathrm{p}>0.05$ ).

\section{Discussion}

This study has evaluated the relations between preeclampsia and common genetic variants in the eNOS gene in a Han Chinese population from mainland China. The population of mainland China accounts for more than $20 \%$ of the population in the world, so it is very im- 


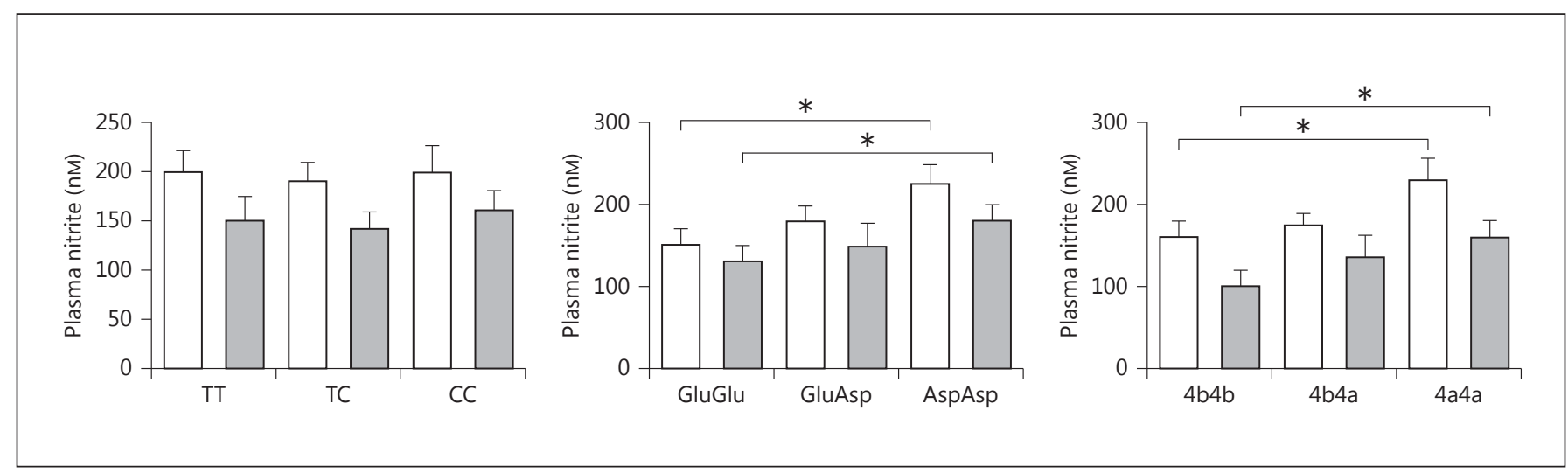

Fig. 1. a-c Plasma nitrite concentrations in control (white bars) and in preeclamptic (grey bars) women grouped by genotype for each polymorphism. ${ }^{*} \mathrm{p}<0.05$.

Table 2. Genotype and allele frequencies of the three polymorphisms analyzed in preeclamptic patients and controls

\begin{tabular}{|c|c|c|c|c|}
\hline & $\begin{array}{l}\text { Preeclampsia } \\
(\mathrm{n}=200)\end{array}$ & $\begin{array}{l}\text { Controls } \\
(\mathrm{n}=180)\end{array}$ & OR (odds ratio) & $\mathrm{p}$ value \\
\hline \multicolumn{5}{|l|}{$4 \mathrm{~b} / \mathrm{a}$} \\
\hline $\mathrm{bb}$ & $161(80.5)$ & $124(68.9)$ & $1.864[1.164-2.986]^{1}$ & 0.012 \\
\hline ba & $37(18.5)$ & $51(28.3)$ & $1{\text { (reference })^{1}}^{1}$ & \\
\hline aa & $2(1.0)$ & $5(2.78)$ & & \\
\hline $\mathrm{b}$ allele & $359(89.8)$ & $299(83.1)$ & $1.768[0.168-2.731]$ & 0.008 \\
\hline a allele & $41(11.2)$ & $61(16.9)$ & 1 (reference) & \\
\hline \multicolumn{5}{|l|}{$\mathrm{T}-786 \mathrm{C}$} \\
\hline $\mathrm{TT}$ & $81(40.5)$ & $74(41.1)$ & $1.095[0.599-2.002]$ & 0.871 \\
\hline TC & $90(45.0)$ & $77(42.8)$ & $1.169[0.643-2.125]$ & 0.649 \\
\hline CC & $29(14.5)$ & $29(16.1)$ & 1 (reference) & \\
\hline $\mathrm{T}$ allele & $252(63.0)$ & $225(62.5)$ & $1.022[0.761-1.371]$ & 0.94 \\
\hline C allele & $148(37.0)$ & $135(37.5)$ & 1 (reference) & \\
\hline \multicolumn{5}{|l|}{ Glu298Asp } \\
\hline GluGlu & $142(71.0)$ & $110(61.1)$ & $2.869[1.257-6.547]$ & 0.011 \\
\hline GluAsp & $49(24.5)$ & $50(27.8)$ & $2.178[0.903-5.250]$ & 0.092 \\
\hline AspAsp & $9(4.5)$ & $20(11.1)$ & 1 (reference) & \\
\hline Glu allele & $333(83.3)$ & $270(75.0)$ & $1.657[1.162-2.362]$ & 0.005 \\
\hline Asp allele & $67(16.7)$ & $90(25.0)$ & 1 (reference) & \\
\hline
\end{tabular}

Results are expressed as numbers with percentages in parentheses; figures in square brackets are $95 \%$ CI. The $p$ value was calculated for difference among groups by the $\chi^{2}$ test.

1 The OR was referred to 'bb' to 'ba + aa'.

portant to understand the role of eNOS polymorphism in Chinese preeclamptic women. However, so far, only one study from Taiwan reported the relationship between eNOS polymorphisms with preeclampsia in a Chinese population. To further confirm and elaborate this related study, we chose only Han Chinese from mainland China to repeat part of this similar study; in addition, we added one more single-nucleotide polymorphism (T-786C) and examined the plasma $\mathrm{NO}$ concentration in each participant as well. The single locus analysis among the three common variants of the eNOS gene (4b/a, T-786C and Glu894Asp) has revealed that, in a Han Chinese popula- 
tion from mainland China, 4b/a and Glu894Asp have a possible association with preeclampsia, whereas T-786C is not associated with this complication, which is consistent with the previous study from Taiwan.

Confusingly, some studies [10,27-32] have reported a positive association between preeclampsia and the variants of the eNOS gene, whereas the two already published meta-analyses and some other individual studies did not report conformity in the replication of the findings [14, 17, 33-35]. Thus, the current evidence available from the candidate gene approach cannot convince us to accept the view of a major contributory role of eNOS variants in the pathogenesis of preeclampsia.

Preeclampsia is a multifactorial and polygenic disorder. The precise etiology of preeclampsia has yet to be determined, but numerous and extensive analyses in transgenic animal models and in genome-wide human studies have been performed to investigate the relation between environmental and genetic factors of this disorder. Some of these studies focusing on the important role of $\mathrm{NO}$ in vascular function have emphasized the relation between eNOS gene polymorphisms and preeclampsia as a vascular disorder. Much attention has been focused on the three of them, namely the T-786C polymorphism in promoter, $4 \mathrm{a} / \mathrm{b}$ polymorphism in intron 4 and the Glu298Asp polymorphism in exon 7 that may reduce NO bioactivity $[24,36]$. In the current study, we examined the plasma NO level in each participant and classified NO levels based on genotypes, by which some novel findings are reported: 2 eNOS polymorphisms (intron 4b/a and Glu894Asp) affect NO formation in both preeclamptic women and healthy women, in whom the 894Asp allele and intron 4a allele are associated with higher nitrite concentrations, and this is consistent with our genotype analysis that the 894Asp allele and intron $4 \mathrm{a}$ are associated with a lower risk of preeclampsia. Our result is partially different from the study of Sandrim et al. [24], which may be due to the different ethnic populations examined.

In conclusion, the present genetic association study replicates a significant association of the eNOS variants with preeclampsia in a Han Chinese population, and these genetic studies confirm that a decreased eNOS activity may be involved in the pathogenesis and development of preeclampsia via its impact on NO production. The results of the present individual gene association study should be interpreted with caution since the participant sample was not large enough. However, preeclampsia is a complex complication with multifaceted etiology and therefore, a contributory pathogenetic role of eNOS variants in the synergistic effect with other genetic or environmental factors seems very impossible [37]. Further collaborative research in preeclampsia may help in elucidating the contributory role of eNOS variants by performing genetic association studies and genomewide association studies with adequate credibility.

\section{Acknowledgment}

We appreciate the funding from Wenzhou Medical University affiliated No. 1 Hospital to support this project.

\section{Disclosure Statement}

We declare that all the authors have no conflict of interest.

\section{References}

1 Grill S, Rusterholz C, Zanetti-Dallenbach R, Tercanli S, Holzgreve W, Hahn S, Lapaire O: Potential markers of preeclampsia - a review. Reprod Biol Endocrinol 2009;7:70.

$\checkmark 2$ Hahn S, Rusterholz C, Hosli I, Lapaire O: Cell-free nucleic acids as potential markers for preeclampsia. Placenta 2011;32(suppl): S17-S20.

-3 Hocher B, Chen YP, Hugle S, Repey J, Krause K, Slowinski T, Godes M, Schaeffeler E, Guthmann F, Wauer R, Halle H, Gossing G, Pfab $\mathrm{T}$ : Impact of maternal endothelial nitric oxide synthase gene polymorphisms on blood pressure, protein excretion and fetal outcome in pregnancy. J Hum Hypertens 2008;22:641647.
4 Song C, Xie S, Wang J, Lian J, Diao B, Tang Y: Association of angiotensinogen gene polymorphisms and angiogenic factors with preeclampsia in Chinese women. Gynecol Obstet Invest 2013;76:64-68.

5 Salimi S, Naghavi A, Mokhtari M, Noora M, Yaghmaei M: Lack of relationship between endothelial nitric oxide synthase gene $4 \mathrm{~b} / \mathrm{a}$ and $\mathrm{T}-786 \mathrm{C}$ polymorphisms with preeclampsia in southeast of Iran. Arch Gynecol Obstet 2012;285:405-409.

6 Kublickiene KR, Lindblom B, Kruger K, Nisell H: Preeclampsia: evidence for impaired shear stress-mediated nitric oxide release in uterine circulation. Am J Obstet Gynecol 2000;183:160-166.
7 Cockell AP, Poston L: Flow-mediated vasodilatation is enhanced in normal pregnancy but reduced in preeclampsia. Hypertension 1997; 30:247-251.

-8 Savvidou MD, Hingorani AD, Tsikas D, Frolich JC, Vallance P, Nicolaides KH: Endothelial dysfunction and raised plasma concentrations of asymmetric dimethylarginine in pregnant women who subsequently develop pre-eclampsia. Lancet 2003;361:1511-1517.

-9 Garcia RG, Celedon J, Sierra-Laguado J, Alarcon MA, Luengas C, Silva F, Arenas-Mantilla M, Lopez-Jaramillo P: Raised C-reactive protein and impaired flow-mediated vasodilation precede the development of preeclampsia. Am J Hypertens 2007;20:98-103. 
10 Sandrim VC, Palei AC, Cavalli RC, Araujo FM, Ramos ES, Duarte G, Tanus-Santos JE: eNOS haplotypes associated with gestational hypertension or preeclampsia. Pharmacogenomics 2008;9:1467-1473.

-11 Landau R, Xie H-G, Dishy V, Wood AJJ, Stein CM, Smiley RM: No association of the Asp298 variant of the endothelial nitric oxide synthase gene with preeclampsia. Am J Hypertens 2004;17:391-394.

-12 Boger RH, Diemert A, Schwedhelm E, Luneburg N, Maas R, Hecher K: The role of nitric oxide synthase inhibition by asymmetric dimethylarginine in the pathophysiology of preeclampsia. Gynecol Obstet Invest 2010;69: 1-13.

13 Arngrimsson R, Hayward C, Nadaud S, Baldursdottir A, Walker JJ, Liston WA, Bjarnadottir RI, Brock DJ, Geirsson RT, Connor JM, Soubrier F: Evidence for a familial pregnancyinduced hypertension locus in the eNOSgene region. Am J Hum Genet 1997;61:354362.

14 Sharma D, Trivedi SS, Bhattacharjee J: Oxidative stress and eNOS (Glu298Asp) gene polymorphism in preeclampsia in Indian population. Mol Cell Biochem 2011;353:189-193.

15 Hingorani AD: Endothelial nitric oxide synthase polymorphisms and hypertension. Curr Hypertens Rep 2003;5:19-25.

16 Zdoukopoulos N, Doxani C, Messinis IE, Stefanidis I, Zintzaras E: Polymorphisms of the endothelial nitric oxide synthase (NOS3) gene in preeclampsia: a candidate-gene association study. BMC Pregnancy Childbirth 2011;11:89.

-17 Yu CK, Casas JP, Savvidou MD, Sahemey MK, Nicolaides KH, Hingorani AD: Endothelial nitric oxide synthase gene polymorphism (Glu298Asp) and development of pre-eclampsia: a case-control study and a metaanalysis. BMC Pregnancy Childbirth 2006;6: 7.

18 Medica I, Kastrin A, Peterlin B: Genetic polymorphisms in vasoactive genes and preeclampsia: a meta-analysis. Eur J Obstet Gynecol Reprod Biol 2007;131:115-126.
19 Tesauro M, Thompson WC, Rogliani P, Qi L, Chaudhary PP, Moss J: Intracellular processing of endothelial nitric oxide synthase isoforms associated with differences in severity of cardiopulmonary diseases: cleavage of proteins with aspartate vs glutamate at position 298. Proc Natl Acad Sci USA 2000;97:28322835.

20 Tsukada T, Yokoyama K, Arai T, Takemoto F, Hara S, Yamada A, Kawaguchi Y, Hosoya $\mathrm{T}$, Igari J: Evidence of association of the ecNOS gene polymorphism with plasma NO metabolite levels in humans. Biochem Biophys Res Commun 1998;245:190-193.

21 Nakayama M, Yasue H, Yoshimura M, Shimasaki Y, Kugiyama K, Ogawa H, Motoyama T, Saito Y, Ogawa Y, Miyamoto Y, Nakao K: $\mathrm{T}-786 \rightarrow \mathrm{C}$ mutation in the $5^{\prime}$-flanking region of the endothelial nitric oxide synthase gene is associated with coronary spasm. Circulation 1999;99:2864-2870.

22 Roberts JM, Gammill H: Pre-eclampsia and cardiovascular disease in later life. Lancet 2005;366:961-962.

23 Sibai B, Dekker G, Kupferminc M: Pre-eclampsia. Lancet 2005;365:785-799.

24 Sandrim VC, Palei AC, Sertorio JT, Cavalli RC, Duarte G, Tanus-Santos JE: Effects of eNOS polymorphisms on nitric oxide formation in healthy pregnancy and in pre-eclampsia. Mol Hum Reprod 2010;16:506-510.

25 Yang BK, Vivas EX, Reiter CD, Gladwin MT: Methodologies for the sensitive and specific measurement of S-nitrosothiols, iron-nitrosyls, and nitrite in biological samples. Free Radic Res 2003;37:1-10.

26 Metzger IF, Sertorio JT, Tanus-Santos JE: Relationship between systemic nitric oxide metabolites and cyclic GMP in healthy male volunteers. Acta Physiol 2006;188:123-127.

27 Serrano NC, Casas JP, Díaz LA, Páez C, Mesa CM, Cifuentes R, Monterrosa A, Bautista A, Hawe E, Hingorani AD, Vallance P, LópezJaramillo P: Endothelial NO synthase genotype and risk of preeclampsia: a multicenter case-control study. Hypertension 2004;44: 702-707.

-28 Bashford MT, Hefler LA, Vertrees TW, Roa BB, Gregg AR: Angiotensinogen and endothelial nitric oxide synthase gene polymorphisms among Hispanic patients with preeclampsia. Am J Obstet Gynecol 2001;184: 1345-1350, discussion 1350-1351.
9 Chen L-K, Huang C-H, Yeh H-M, Lee C-N, Shyu M-K, Hsieh F-J, Lai L-P, Sun W-Z: Polymorphisms in the endothelial nitric oxide synthase gene may be protective against preeclampsia in a Chinese population. Reprod Sci 2007; 14:175-181.

30 Fatini C, Sticchi E, Gensini F, Genuardi M, Tondi F, Gensini GF, Riviello C, Parretti E, Mello G, Abbate R: Endothelial nitric oxide synthase gene influences the risk of pre-eclampsia, the recurrence of negative pregnancy events, and the maternal-fetal flow. J Hypertens 2006;24:1823-1829.

31 The significance of $-786 \mathrm{~T}>\mathrm{C}$ polymorphism of endothelial NO synthase (eNOS) gene in severe preeclampsia. J Maternal Fetal Neonatal Med 2011;24:432-436.

32 Aggarwal PK, Jain V, Jha V: Endothelial nitric oxide synthase, angiotensin-converting enzyme and angiotensinogen gene polymorphisms in hypertensive disorders of pregnancy. Hypertens Res 2010;33:473-477.

33 Medica I, Kastrin A, Peterlin B: Genetic polymorphisms in vasoactive genes and preeclampsia: a meta-analysis. Eur J Obstet Gynecol Reprod Biol 2007;131:115-126.

34 Hillermann R, Carelse K, Gebhardt GS: The Glu298Asp variant of the endothelial nitric oxide synthase gene is associated with an increased risk for abruptio placentae in pre-eclampsia. J Hum Genet 2005;50:415-419.

35 Tempfer CB, Jirecek S, Riener EK, Zeisler H, Denschlag D, Hefler L, Husslein PW: Polymorphisms of thrombophilic and vasoactive genes and severe preeclampsia: a pilot study. J Soc Gynecol Investig 2004;11:227-231.

36 Casas JP, Cavalleri GL, Bautista LE, Smeeth L, Humphries SE, Hingorani AD: Endothelial nitric oxide synthase gene polymorphisms and cardiovascular disease: a huge review. Am J Epidemiol 2006;164:921-935.

37 Clayton D, McKeigue PM: Epidemiological methods for studying genes and environmental factors in complex diseases. Lancet 2001; 358:1356-1360. 